\title{
OVEREXPRESSION OF ARABIDOPSIS BBX 21 GENE IN BG 250 RICE ENHANCES ITS ARCHITECTURE AND PRODUCTIVITY
}

\author{
R.M.L.K. Ratnayaka ${ }^{1}$, G.A.U. Jayasekera ${ }^{2}$ and G.H.C.M. Hettiarachchi1,", \\ ${ }^{1}$ Department of Chemistry, University of Colombo, Colombo 3, Sri Lanka \\ ${ }^{2}$ Department of Plant Sciences, University of Colombo, Colombo 3, Sri Lanka \\ *corresponding author email: chamarih@chem.cmb.ac.lk
}

\begin{abstract}
Arabidopsis BBX21 protein was identified as a transcription activator which can activate the light dependent transcription and positively regulate light mediated development of plants. The productivity of crop plants can be enhanced by over-expressing central regulators of light signaling pathway. The present study was conducted to enhance the productivity of $\mathrm{Bg} 250$ Sri Lankan rice variety by overexpressing Arabidopsis BBX21 gene. The BBX21 gene was cloned into pPZP 200 binary vector and the cloned vector gene construct was transformed into Agrobarcteium tumefaciens GV3101 strain by freeze thaw method. The selected recombinant colonies of A. tumefaciens strain GV3101 harboring BBX 21 gene were transformed into three weeks old $\mathrm{Bg} 250$ rice callus. Selection of the transformed callus was conducted on $\mathrm{N}_{6} \mathrm{~B}_{5}$ selection medium containing $50 \mathrm{mg} / \mathrm{L}$ gentamycin and $500 \mathrm{mg} / \mathrm{L}$ cefotaxime. A total of putative 83 plants which showed resistant to gentamycin were subjected to PCR analysis and the results showed 69 of the regenerated plants are transgenic. The $\mathrm{T}_{1}$ seeds collected from putative transgenic plants were characterize to check its integration and inheritance. The transgenic plants which showed 3:1 ratio was selected and further grown to obtain its homozygous lines. The expression of BBX21 gene was demonstrated by northern blot analysis and the results showed 4 fold higher expression of BBX21 gene in the transgenic plants compared with its non-transgenic wild type plants. The phenotypic analysis of homozygous BBX21 transgenic plants showed improved plant height, leaf length, leaf area, number of panicles and bushy appearance compared with its non-transgenic plants. Taken together, these results demonstrate an involvement of BBX21 gene in rice modifying architecture and productivity of $\mathrm{Bg} 250$ transgenic plants.
\end{abstract}

Key words: Arabidopsis BBX21; Agrobacterium tumefacience; Bg 250 transgenic plants; Plant architecture.

\section{Introduction}

Rice is the single most important crop in Sri Lanka, occupying $34 \%(0.77 /$ million ha) of the total cultivated area. Sri Lanka currently produces 2.7 million tons of rice annually and satisfies around $95 \%$ of the domestic requirement. Rice provides $45 \%$ total calorie and $40 \%$ total protein requirement of an average Sri Lankan. The per capita consumption of rice fluctuates around $100 \mathrm{~kg}$ per year depending on the price of rice and wheat flour. It has been projected that the demand for rice will increase at $1.1 \%$ per year and to meet the demand, rice production should grow at the rate of $2.9 \%$ per year. Hence, to meet the growing needs of the population, it is necessary to produce more rice or to improve existing rice varieties in the future. This goal could be achieved by increasing the productivity of existing rice varieties by altering its light signaling pathway and photosynthetic rate.

Light is one of the most important factor that influences plant growth and development. A dramatic example of light signaling can be seen during seedling de-etiolation (Kami et $a l, 2010)$ which higher plants are intrinsically program with two developmental plans; skotomorphogenesis and photomorphogenesis. This process is introduced by wavelength specific photoreceptors and entails a dramatic transcriptional reprogramming (Lakshmanan et al., 2015, Raghuram et al., 2014). COP1 and HY5 are two key regulators in seedling development. The bZIP transcription factor HY5, acts downstream of several photoreceptors, is a positive regulator of light signaling pathway which directly binds to promoters of light inducible gene to activate photomorphogenic development (Chattopadyay et al., 1998). COP1, an E3 ubiquitin ligase, represses light dependent development by targeting positive factors such as the transcription factor HY5 for degradation in the dark (Wang and Deng, 2002). ). HY5 regulates the expression of light responsive gene Ribulose 1, 5 bisphosphate carboxylase/oxygenase (RUBISCO), one of the key enzyme that catalyzes an important step in photosynthesis (Chattopadyay et al., 1998). The BBX21, a B-box containing protein can activate transcription and positively regulate light mediated development in Arabidopsis by interacting with the COP1 and HY5 of light signaling 
pathway (Datta et al, 2007). Considering the above facts, we hypothesized BBX21 might enhance the activity of photosynthesis genes in plants through HY5 mediated transcriptional activation, resulting improved photosynthetic rate.

The productivity of crop plants might be enhanced by over expressing central regulators of light signaling pathway (Smith, 1992). Thiele et al in 1999 showed the over expression of the Arabidopsis Phy-B photoreceptor in potato has increased the yield, both in gross weight and in number of tubers. Over expression of Arabidopsis Phy A in basmati rice resulted in an approximately $20 \%$ increase in yield (Wu et al., 2005). Further, overexpression of oat Phy A in tobacco plants showed light exaggerated phenotype under white light. Phy-A over expressing plants consistently express higher amounts of several enzymes of carbon metabolism and many genes involved in photosynthesis are coordinately regulated by phytochrome (Sharkey et al., 1991). Phy-C over expressing transgenic tobacco plants shows increased leaf area and plant size, these traits can be exploited in some field crops where it is directly leads to increase in productivity (Halliday et al., 1997). All of the findings demonstrated that overexpression of light regulatory proteins can increase the photosynthetic performance, will have tremendous potential in crop improvement. Recently, most of the research groups have paid their attention on developing abiotic stress tolerance plants and little attention was given on enhancing the productivity of crop plants. Hence, understanding the light signaling pathways and utilizing the knowledge to improve the genetic potential of crops could be an important goal of plant biotechnology research to improve its productivity.

Bg 250 is an improved Sri Lankan rice variety with high quality grains, resistance to leaf blast, bacterial leaf blight, thrips and brown plant-hopper. This is an ultra-short duration variety that matures in about 80 days and also suitable for drought and flood-prone areas. In the former, it can escape from drought, if planted early; in the latter, it can escape from flood if planted after the flood has receded, yielding well before the subsequent dry period. In spite of all the valuable qualities it gives very low yield. The productivity of this variety may be increased by genetic manipulation of light regulatory pathway by overexpressing BBX 21 gene could be the best answer to meet the growing need in the country. Hence, $\mathrm{Bg} 250$ Sri Lankan rice variety was selected as the candidate rice variety to increase its productivity by over-expressing Arabidopsis BBX21 gene.

The present research was focused on transforming pPZP200-BBX21 vector gene construct into three weeks old Bg 250 rice calli via Agrobacterium mediated transformation protocol to obtain BBX21 transgenic plants. The regenerated BBX21 transgenic plants were subjected to molecular and phenotypic analysis and results showed the overexpression of Arabidopsis BBX 21 gene in $\mathrm{Bg} 250$ rice enhances rice plants architecture and productivity.

\section{Materials and Methods \\ Plant materials and growth conditions}

Rice seeds of Oryza sativa L., indica, Bg-250, was obtained from the Rice Research and Development Institute, Bathalegoda, Ibbagamuwa,Sri Lanka was used as explants to induce embryogenic calli. The regenerated transgenic plants were grown in a greenhouse maintained under $16 \mathrm{~h}$ of light $\left(150 \mu \mathrm{E} \mathrm{m}^{-2} \mathrm{~s}^{-1}\right)$ at $28^{\circ} \mathrm{C}$ and $8 \mathrm{~h}$ of dark at $18^{\circ} \mathrm{C}$.

\section{Bacterial strains and Plasmids}

Escherichia coli (DH5 $\alpha$ strain) and Agrobacterium tumefaciens (GV 3101), pPZP200, and pPZP200-BBX21 were provided by Department of Cell and Molecular Biology, University of Gothenburg, Sweden.

\section{Characterization of vector gene constructs}

pPZP200-BBX21 vector gene construct provided by the Department of Cell and Molecular Biology, University of Gothenburg, Sweden was reconfirmed before transforming into Agrobacterium. The isolated plasmid DNA was subjected to PCR amplification using CaMV35S promoter specific forward and gene specific reverse primer pair and restriction enzyme digestion was carried out with EcoR1 in order to confirm the presence of BBX21 gene.

\section{Transformation, selection and regeneration of Bg 250 rice plants}

Transformation, selection and plant regeneration of $\mathrm{Bg} 250$ were conducted as described in Rathnayaka and Hettiarachchi 2010. A single colony of A. tumefaciens (GV3101) harboring a binary vector, pPZP 200 with BBX21 gene was picked from a freshly grown plate and inoculated into $5.0 \mathrm{ml}$ of LB broth supplemented with 100 $\mathrm{mg} / \mathrm{L}$ Streptomycin and 25mg/L Rifampicin and allowed to grow until the $\mathrm{O}_{600}$ reached 1.0. The culture was centrifuged at $3500 \mathrm{rpm}$ for 10 minutes and the pellet was re-suspended in liquid $\mathrm{N}_{6} \mathrm{~B}_{5}$ medium containing $20 \mathrm{~g} / \mathrm{L}$ sucrose, $10 \mathrm{~g} / \mathrm{L}$ glucose and 50/100/150 $\mu \mathrm{M}$ acetosyringone. The calli of Bg-250 were dipped in bacterial suspension for 5 minutes, and infected calli transferred onto $\mathrm{N}_{6} \mathrm{~B}_{5}$ cocultivation medium at $28^{\circ} \mathrm{C}$ for 2 days. After incubation the calli were washed with sterile distilled water and a series of aqueous solutions containing $1 \mathrm{~g} / \mathrm{L}, 750 \mathrm{mg} / \mathrm{L}$ and 500 $\mathrm{mg} / \mathrm{L}$ Cefotaxime and incubated under same conditions. After two weeks, the calli were transferred on $\mathrm{N}_{6} \mathrm{~B}_{5}$ selection medium containing $50 \mathrm{mg} / \mathrm{L}$ Gentamycine and $500 \mathrm{mg} / \mathrm{L}$ Cefotaxime. In a another 2 weeks' time healthy portions of the calli on selection medium were sub-cultured onto a fresh selection medium, and incubated under light. The well-developed calli with shoot primordia were subcultured on $\mathrm{N}_{6} \mathrm{~B}_{5}$ shoot regeneration medium containing 50 $\mathrm{mg} / \mathrm{L}$ Gentamycine and $500 \mathrm{mg} / \mathrm{L}$ Cefotaxime in jam jars and incubated at $28{ }^{\circ} \mathrm{C}$ with continuous light. Healthy shoots with defined stem were transferred to MS rooting medium (Murashige and Skoog, 1962) containing $50 \mathrm{mg} / \mathrm{L}$ 
Gentamycine and $500 \mathrm{mg} / \mathrm{L}$ Cefotaxime in jam jars and incubated at $28{ }^{\circ} \mathrm{C}$ with continuous light. Plantlets with well-developed root system were up-rooted from the culture vessel and washed with lukewarm water to remove agar. They were dipped in fungicide solution (SHOOT) with 250 $\mathrm{mg} / \mathrm{L}$ concentration and transferred to $250 \mathrm{ml}$ plastic pots containing autoclaved mud collected from rice fields. The plantlets were established in such a way that the clump of plantlets originated from each calli were separated carefully and planted in several pots. The pots were maintained in a shady place and high humidity for two weeks before they were transferred to the plant house. The regenerated plants were maintained in the plant house under $16 \mathrm{~h}$ of light $(150$ $\left.\mu \mathrm{E} \mathrm{m} \mathrm{m}^{-2} \mathrm{~s}^{-1}\right)$ at $28^{\circ} \mathrm{C}$ and $8 \mathrm{~h}$ of dark at $18^{\circ} \mathrm{C}$ until it produced seeds.

\section{Confirmation of integration and inheritance}

Matured seeds were collected separately from each putative transgenic plants were screened on $50 \mathrm{mg} / \mathrm{L}$ Gentamycin plates. The plants that showed resistance to gentamycine was transformed onto soil and further grown until it produced seeds. The seeds were collected separately from each plants (Around 60 to 70 seeds from each plant) was screened on $50 \mathrm{mg} / \mathrm{L}$ Gentamycin plates to select plants that showed 3:1 ratio (single insertion). Ten plants that showed 3:1 ration were selected and grown until it reach to its homozygous lines. Homozygous transformants of the $\mathrm{T}_{3}$ generation were selected for Molecular and phenotypic analysis.

\section{PCR analysis and sequencing}

Genomic DNA was isolated from fresh leaf of transgenic plants and untransformed control plants by the cetyltrimethylammonium bromide (CTAB) method (Saghai Marrof et al, 1984). Equal amount of $100 \mathrm{ng}$ of total DNA were amplified in $25 \mu 1$ reactions using CaMV 35S specific forward primer (5' CCA CGT CTT CAA AGC AAG TGG 3') and Arabidopsis BBX21 gene specific reverse primer (5' TTA CCA GAA AGA TCT AAA CTT TTT AT 3'). PCR amplifications were carried out with an initial denaturation at $95^{\circ} \mathrm{C}$ for 3 minutes followed by 30 cycles $95^{\circ} \mathrm{C}-25 \mathrm{~s}$, at $53{ }^{\circ} \mathrm{C}-1 \mathrm{~min}$, at $72{ }^{\circ} \mathrm{C}-3 \mathrm{~min}$ and final extension at $72{ }^{\circ} \mathrm{C}$ for $15 \mathrm{~min}$. The PCR products were electrophoresed on $1 \%$ (w/v) agarose gel to check for amplification. $50 \mu 1$ of 50 $\mathrm{ng} / \mu \mathrm{l}$ purified PCR product along with $20 \mu \mathrm{l}$ of $10 \mathrm{p}$ mole/ $\mu \mathrm{l}$ primers were sent to Macrogen Inc. (Korea) for sequencing.

\section{Phenotypic characterization}

Phenotypic characterization and plant fertility of homozygous $\mathrm{T}_{3}$ generation transformants and non- transformants were determined under greenhouse conditions. All the plants were irrigated daily. Data were collected for following parameters: appearance of plants, plant height, and number of tillers, filled panicles, number of seeds per panicles, leaf length and area.

The phenotypic data collected on leaf area, leaf length, number of panicles and number of seeds per panicle from transformed and untransformed plants. $(n=25)$ These data were analyzed by SPSS version 20 using one way ANOVA.

\section{Transcript analysis of $\mathrm{BB} X 21$ gene}

For Northern blot analysis, about $0.1 \mathrm{~g}$ of tissues were used for each sample for isolation of RNA by the Trizol method (Hettiarachchi et al., 2003). Total RNA ( 25-30 $\mu \mathrm{g})$ from transgenic and non-transgenic plants were fractionated on $1 \%$ denaturing formaldehyde gels. The blotting, preparation of probe and hybridization was carried out as described in Hettiarachchi et al. 2003.

\section{Results and Discussion}

\section{Bg 250 rice plant transformation and regeneration}

The restriction digestion analysis and PCR amplification results confirmed the presence of correct size of gene in pPZP 200 plant binary vector (results are not shown). The pPZP 200 plant binary vector harboring the fragment of CaMV 35S promoter and Arabidopsis BBX21 cDNA (Fig. 1) was transformed into A. tumefaciens GV 3101 using freeze thaw method (Rathnayaka \& Hettiarachchi 2010). The colony PCR was conducted with CaMV 35S promoter specific primers to amplify $130 \mathrm{bp}$ of CaMV 35S specific promoter region. All the colonies used in colony PCR showed the amplification of $130 \mathrm{bp}$ fragment were selected for further studies (Data not shown).

It was reported that immature embryos or mature seed derived calli are the most suitable explants for in vitro plant regeneration in rice and the most suitable ex-plant for $A$. tumefaciens mediated transformation is scutellum derived calli (Christou, 1996). Some reports used immature embryo derived calli (Dong et al, 1996), but others found that calli initiated from scutellum of mature seeds were excellent starting material for in vitro rice plant regeneration and transformation by A. tumefaciens due to their compactness (Rashid et al, 2001, 2004, Cho et al, 2004). We used Bg 250 mature seeds to obtain scutellum derived calli and the three weeks old calli were transformed with A. tumefaciens $\mathrm{GV}$ 3101 strain harboring binary vector pPZP200 and BBX21 (Fig. 2 A).

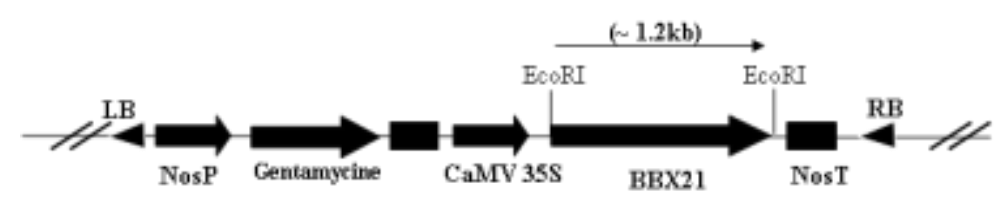

Fig. 1: The schematic diagram showing the gene construct containing CaMV 35S as the constitutive promoter, BBX21 cDNA sequence and the Nos as the terminator between LB and the RB of pPZp200 plant binary vector. 
R.M.L.K. Ratnayaka et al. (2016) Int J Appl Sci Biotechnol, Vol 4(2): 240-246

Table 1: Callus induction, regeneration and transformation efficiencies of transgenic $\mathrm{Bg} 250$ and wild type $\mathrm{Bg}$ 250. $(\mathrm{n}=25)$

\begin{tabular}{|l|l|l|l|}
\hline Rice variety & $\begin{array}{l}\text { Callus } \\
\text { induction } \\
\text { efficiency }\end{array}$ & $\begin{array}{l}\text { Regeneration } \\
\text { efficiency }\end{array}$ & $\begin{array}{l}\text { Transformation } \\
\text { Efficiency }\end{array}$ \\
\hline TransgenicBg250 & $32 \%$ & $70 \%$ & $22 \%$ \\
\hline Wild type Bg 250 & $47 \%$ & $75 \%$ & $30 \%$ \\
\hline
\end{tabular}

The transformants were selected on $\mathrm{N}_{6} \mathrm{~B}_{5}$ selection medium containing $50 \mathrm{mg} / \mathrm{L}$ gentamycin and $500 \mathrm{mg} / \mathrm{L}$ cefotaxime in the dark for 2 weeks at $28{ }^{\circ} \mathrm{C}$. (Fig. 2B). After that, the calli were transferred to fresh regeneration medium and incubated in growth chamber maintained under $16 \mathrm{~h}$ of light $\left(150 \mu \mathrm{E} \mathrm{m}^{-2} \mathrm{~s}^{-1}\right)$ at $28^{\circ} \mathrm{C}$ and $8 \mathrm{~h}$ of dark at $18^{\circ} \mathrm{C}$. The welldeveloped calli with shoot primordia were sub-cultured on $\mathrm{N}_{6} \mathrm{~B}_{5}$ shoot regeneration medium containing $500 \mathrm{mg} / \mathrm{L}$ cefotaxime and incubated at $28{ }^{\circ} \mathrm{C}$ with same light conditions as above (Fig. 2C). Healthy shoots with defined stem were transferred to MS rooting medium (Murashige and Skoog, 1962) containing $500 \mathrm{mg} / \mathrm{L}$ cefotaxime in glass jars and incubated at $28^{\circ} \mathrm{C}$. (Fig. 2D). The Bg 250 plantlets with well-developed root system were observed after 6 days. After two weeks 83 plants that showed resistance to Gentamycin were carefully transferred to soil pots (Fig. 2E) and maintained in the green house maintained under $16 \mathrm{~h}$ of light $\left(150 \mu \mathrm{E} \mathrm{m}^{-2} \mathrm{~s}^{-1}\right)$ at $28^{\circ} \mathrm{C}$ and $8 \mathrm{~h}$ of dark at $18^{\circ} \mathrm{C}$ until it produced seeds. The results of callus induction, regeneration and transformation efficiency of transgenic and non-transgenic plants were shown in Table 1.

\section{PCR analysis and sequencing of transgenic Bg 250 rice plants}

A total of 83 plants were regenerated from 117 of transformed $\mathrm{Bg} 250$ callus. All putative transgenic plants and untransformed control plants were analyzed by PCR amplification and 69 of them had specific 1405 bp band of CaMV 35S promoter and BBX21 gene. The size of PCR product was confirmed by gel- electrophoresis (Fig. 3). The amplified product was sequenced to confirm the resulted PCR product as the Arabidopsis BBX21coding region. 1405 bp length PCR product was subjected to unidirectional sequencing and similarity search was performed for resulted nucleic acid sequence using the Basic Local Algorithmic Search Tool (BLAST) at the National Center for Biotechnology Information (NCBI). The sequence showed $100 \%$ similarity with Arabidopsis thaliana chromosome 1- complete sequence and genomic sequence for Arabidopsis thaliana BAC F10A5 - complete sequence with E- Value of zero. (Data not shown) Furthermore it showed 99\% similarity to Arabidopsis thaliana putative salt tolerance-like protein (STH2) mRNA currently name as BBX21, complete cds and Arabidopsis thaliana At1g75540 mRNA for hypothetical protein partial cds ( clone: RAAt1g75540) with an e - value of zero.
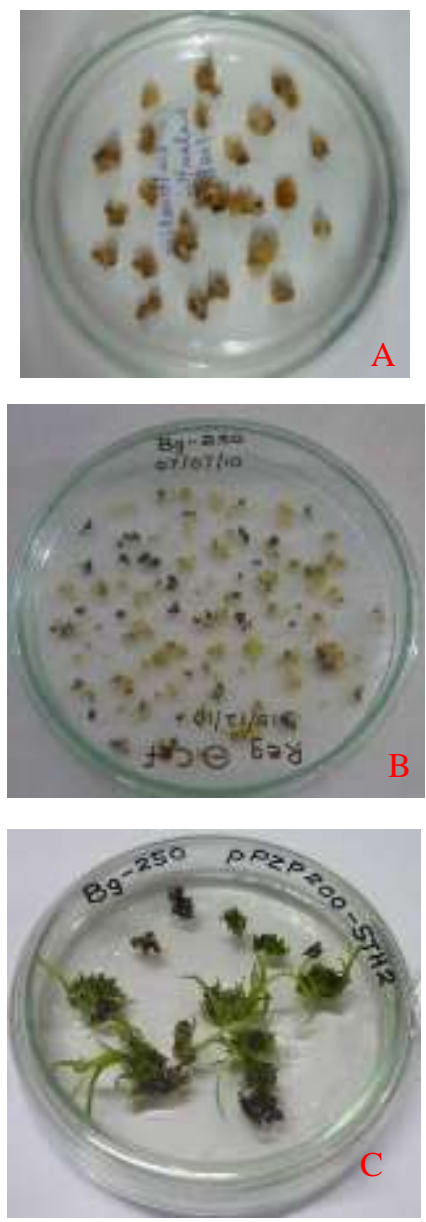
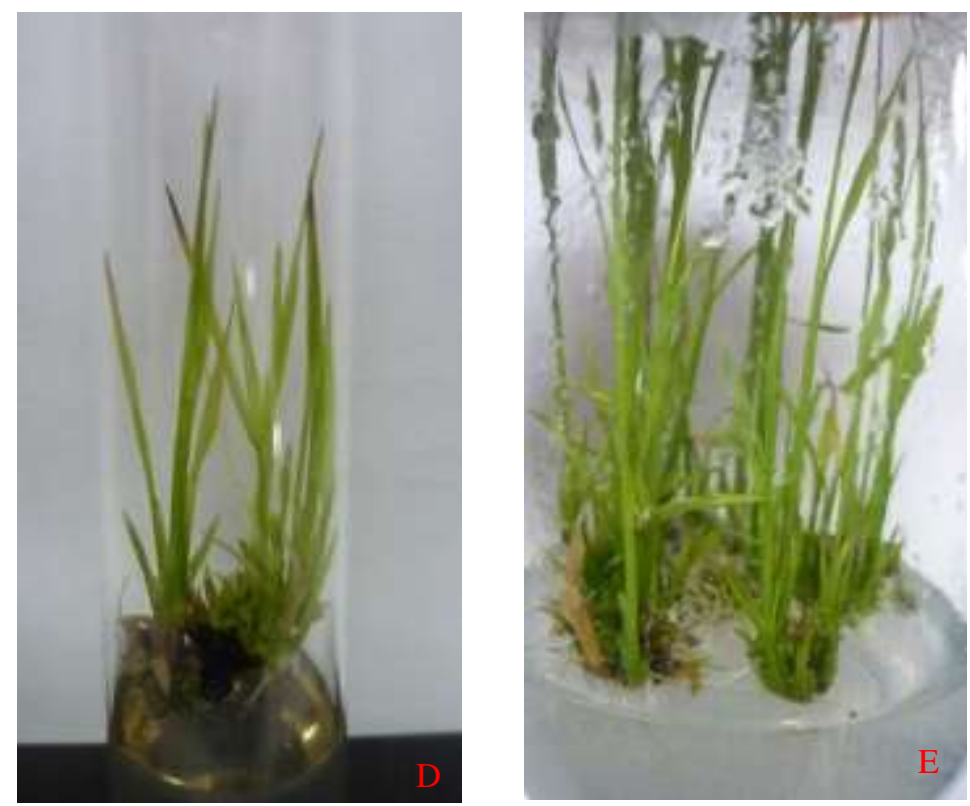

Fig. 2: Regeneration of Arabidopsis BBX21 over expressing Bg 250 from scutellum derived rice calli after Agrobacterium mediated transformation. (A) Scutellum derived calli on co-cultivation medium (B) Gentamycin resistant proliferating calli on shoot regeneration medium, (C) \& (D) regenerated shoots on shoot regeneration medium, (E) plantlets on rooting medium. 


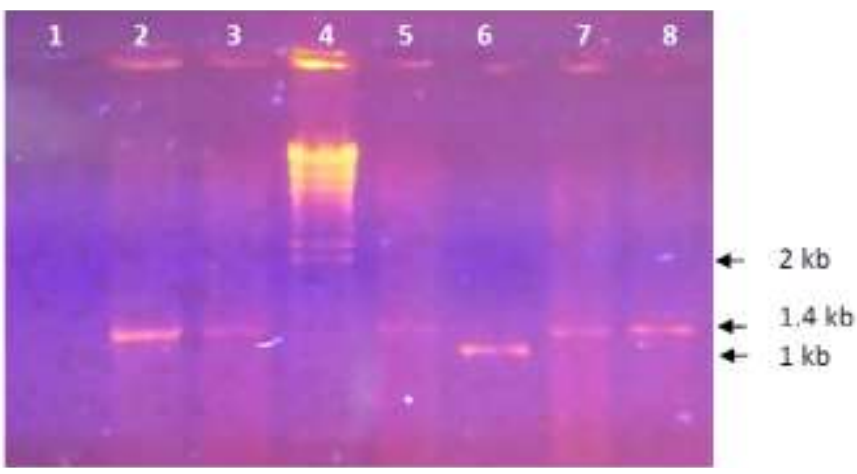

Fig. 3: PCR analysis of transgenic plants.

[Lane 1: negative control; Lane 2: plasmid pPZP200-BBX21 as positive control; Lane 3, 5, $7 \& 8$ : BBX21 gene amplification from transgenic plants; Lane 4: $\lambda$ marker . Lane 6: 1000bp size marker fragment.]
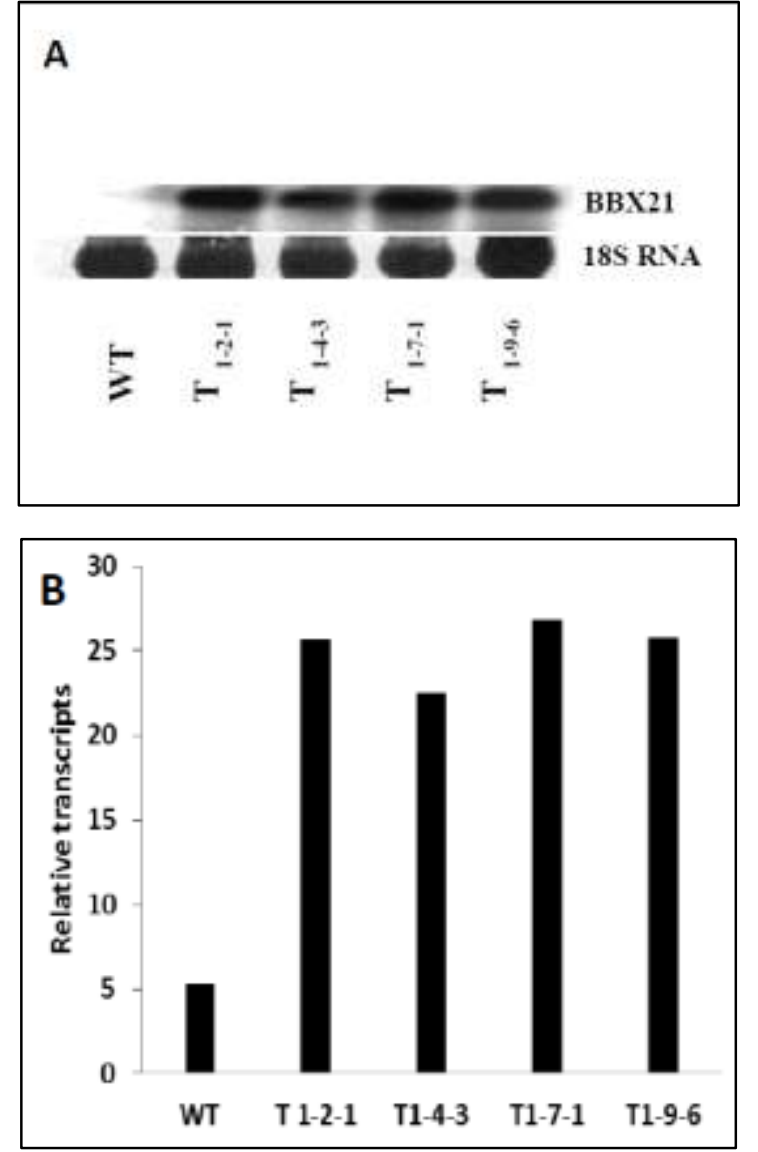

Fig. 4: BBX21 transcripts in Bg 250 transgenic plants (A) The RNA gel blot showing BBX21 transcripts accumulation in $\mathrm{T}_{3}$ transgenic plants and wild type at 10 days after germination. Full length BBX21 gene was used as the probe. 18S RNA bands are shown as loading control. (B) Quantification of the data in (A) by Fluor-S- MultiImager (Biorad)

\section{Expression of BBX21 gene in Bg250 transgenic rice plants}

To determine the expression of BBX21 gene in $\mathrm{Bg} 250$ transgenic rice plants, transcript analysis was carried out with 10 days old transgenic $\mathrm{Bg} 250$ plants in $\mathrm{T}_{3}$ generation. The total RNA was isolated from 10 days old homozygous $T_{3}$ transgenic plants $\left(T_{1-2-1}, T_{1-4-3}, T_{1-7-1}\right.$, and $\left.T_{1-9-6}\right)$ which showed a single gene integration with $3: 1$ ratio in genetic screening. The total RNA isolated from non-transgenic plants were used as the control. All four $\mathrm{T}_{3}$ homozygous transgenic plants showed similar level of expression of Arabidopsis BBX21 gene in $\mathrm{Bg} 250$ rice (Fig. 4 A \& B). Compared to the control, the $\mathrm{T}_{3}$ transgenic plants showed four to five fold higher level of expression of BBX21 gene (Fig. 4 B). The transcript analysis data of four independent $\mathrm{T}_{3}$ transgenic lines results revealed the strong expression of BBX 21 gene in transgenic Bg250 plants.
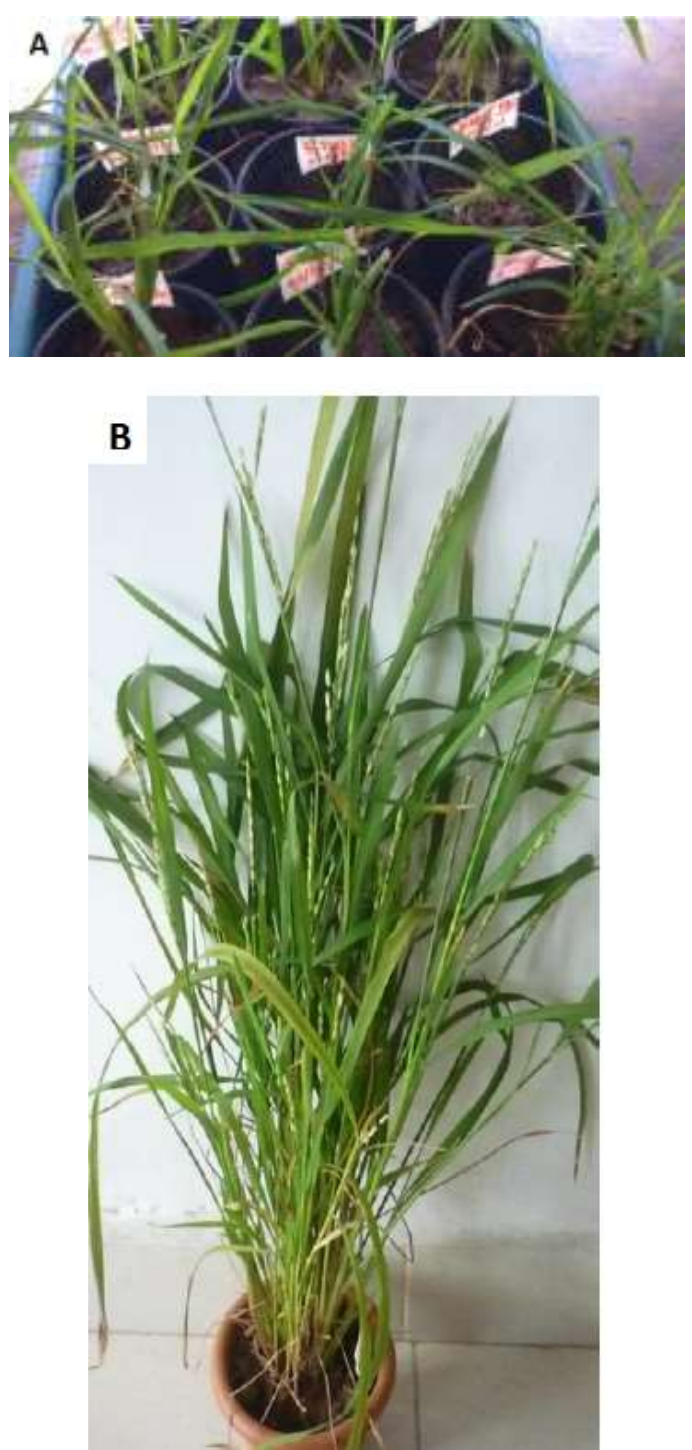

Fig. 5: Arabidopsis BBX21 gene over expressing Bg250 transgenic rice plants. (A)- Acclimatization of gentamycin resistant transformed Bg 250 rice plantlets. (B)- Fully grown transgenic $\mathrm{Bg} 250$ rice plants

\section{Phenotypic analysis of transgenic Bg250 plants}

Phenotypic characterization of Arabidopsis BBX21 gene over-expressing transgenic $\mathrm{Bg} 250$ plants were conducted for plant height, leaf area, leaf length, number of panicles, number of seeds per panicle, and appearance of the transgenic plants and the results of transgenic were compared with the non-transgenic Bg250 plants. All BBX21 gene over expressing transgenic plants and Bg250 non-transgenic plants were grown under the same greenhouse condition as mentioned above (Fig. 5). But the 
transgenic plants were isolated from non-transgenic plants by keeping in a special cage in order to prevent pollen distribution through wind, insects and other ways. Compared to the non-transgenic plants, transgenic Bg 250 plants showed increased plant height and tillering with more bushy appearance (Fig. 5). The resulted tall, bushy plants suggested a strategy whereby the manipulation of light signaling pathways may generate indica lines more resistant to water lodging and with a greater potential to respond positively to fertilizers as the crop productivity is a function of both availability and proportioning of resources. A further potential benefit of increased branching results from potential yield grains. In contrast to a plant such as maize, axillary branches in rice produce productive tillers (Sawers et al, 2005). Therefore, an increased branching will results in an increased in panicle number (Fig. 6 C). Arabidopsis $\mathrm{BBX} 21$ gene over-expressing $\mathrm{Bg} 250$ rice plants displayed significant increase in leaf area and leaf length when compared with non-transgenic $\mathrm{Bg} 250$ rice plants (Fig. $6 \mathrm{~A}$ \& B). This leads to higher photosynthetic performance, which allows grater biomass production and ultimately higher yield in transgenic plants. In 1997 Halliday et al, reported increased leaf area in Arabidopsis PhyC overexpressing tobacco plants. Ectopic expression of the Arabidopsis PHYB (phytochrome B) gene, a photoreceptor involved in detecting red to far-red light ratio associated
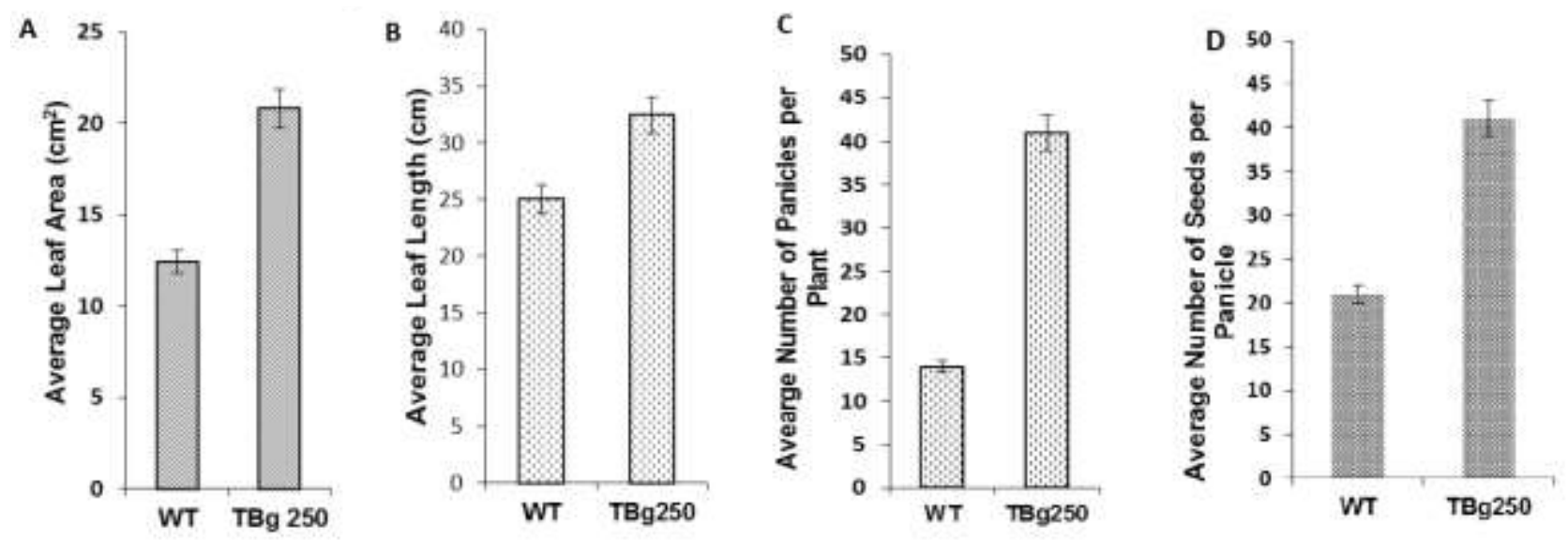

Fig. 6: Phenotypic analysis of transgenic Bg250 (TBg250) and non-transgenic wild type (WT)

(A) Average leaf area (B) Average leaf length (C) Average number of panicles per plants (D) Average number of filled seeds per panicle were measured in twenty five wild type Bg 250 and twenty five homozygous transgenic Bg 250 plants at same age. The error bars indicate the SD from three independent experiments

\section{Conclusion}

We have succeeded in the development of high yielding rice plants by overexpressing BBX 21 gene in Bg 250 Sri Lankan rice variety using Agorbacterium mediated gene transformation system. Overexpression of BBX21 gene in transgenic plants can enhance plant height, number of panicles and number of filled seeds in a panicle. The present study provides and alternative approach for improving high yielding capacity in all crop plants. with plant density, can increase tuber yield in field-grown transgenic potato (Solanum tuberosum) crops (Boccalandro et al,2003). Under greenhouse conditions, increased panicle number and panicle number with filled seeds in transgenic lines were found to correlate with an increased overall grain yield per plant ((Halliday et al., 1997). All the transgenic lines tested were found to produce a higher number of panicles per plant than the non-transgenic lines (Fig. $6 \mathrm{C} \&$ D). Increased panicle production in transgenic lines mainly contributes to the increased number of grain production. Considering all phenotypic data presented, the overexpression of BBX 21 gene in $\mathrm{Bg} 250$ might change the architecture between transgenic and non-transgenic Bg250 plants. Further investigations may be needed to determine the appropriate relationship between the plant architecture and the grain yield. The characterization of the $\mathrm{Bg} 250$ transgenic rice lines are in progressed and that would help to elucidate the role of light signaling in plant development, plant stature and architecture, and ultimately increase in grain yield. Finally this study can be extended to other rice varieties, or other monocot crop plants, it would provide an additional means to produce high yielding plants that can be used as a donor in breeding programs towards the creation of varieties that are fully integrated with the demands of modern cultivation with the aim of contributing to the food demand in the world. 
M H, University of Gothenburg for providing Agrobacterium GV3101 strain and pPZP 200 vector, the Department of Plant Sciences, University of Colombo for providing green house facility, the Department of Chemistry, University of Colombo for providing laboratory facility, and Rice Research and Development Institute, Batalegoda got providing Bg 250 seeds

\section{References}

Boccalandro HE, Ploschuk EL, Yanovsky MJ, Sanchez RA, Gatz C and Casal JJ (2003) Increased phytochrome B alleviates density effects on tuber yield of field potato crops. Plant Physiol. 133: 1539-1546. DOI: $10.1105 /$ tpc.107.054791

Chattopadhyay S, Puente P, Deng XW and Wei N (1998) Combinatorial interaction of light - responsive elements plays a critical role in determining the response characteristics of light-regulated promoters in Arabidopsis. Plant Journal. 15: 69-77. DOI: 10.1105/tpc.107.054791

Cho-J H, Hur-HanSun and Lee-JangYong (2004) Screening of Korean rice cultivars for their shoot regeneration ability In-vitro and the effect of maltose on shoot regeneration. Korean Journal of Breeding 35(4): 229-236.

Christou P (1996) Transformation technology. Trends in Plant Sci. 1:423-431.

Datta S, Hettiarachchi C, Johansson H and Holm M (2007) SALT TOLERANCE HOMOLOG 2 , a B-Box protein in Arabidopsis that activates Transcription and Positively Regulates Light -Mediated development. The plant cell 19: $3242-3255$. DOI: $10.1105 /$ tpc. 107.054791

Dong J, Albertini DF, Nishimori K, Kumar TR, Lu N and Matzuk MM (1996) Growth differentiation factor-9 is required during early ovarian folliculogenesis. Nature 531-535. DOI: $10.1038 / 383531 \mathrm{a} 0$

Halliday KJ, Thomas B and Whitelam GC (1997) Expression of heterologous phytochrome $\mathrm{A}, \mathrm{B}$ or $\mathrm{C}$ in transgenic tobacco plants alter vegetative development and flowering time. Plant Journ. 12: 1079-1090. DOI: 10.1046/j.1365313X.1997.12051079.x

Hettiarachchi GHCM, Yadav V, Reddy MK, Chattopadhyay S and Sopory SK (2003) Light mediated regulation defines a minimal promoter region of TOP2. Nucleic Acid Res. 31: 5256-5265. DOI: $10.1093 / \mathrm{nar} / \mathrm{gkg} 744$

Kami C, Lorrain S, Hornitschek P and Fankhauser C (2010) Light regulate plant growth and development Cuur. Topics in Dev. Biology 91: 29-66

Lakshmanan M, Lim SH, Mohanty B, Kim JK, Ha SH and Lee DY (2015) Unraveling the Light-Specific Metabolic and Regulatory Signatures of Rice through Combined in Silico Modeling and Multiomics Analysis. Plant Physiol. 169(4): 3002-3020.
Murashige T and Skoog F (1962) A revised medium for rapid growth and bioassays with tobacco tissue culture. Plant Physio. 15: 473-497. DOI: 10.1111/j.13993054.1962.tb08052.x

Raghuram B, Sheikh AH and Sinha AK (2014) Regulation of MAP kinase signaling cascade by microRNAs in Oryza sativa. Plant Signal Behav. 9(10): e972130. DOI: 10.4161/psb.29804

Rashid H, Bokhari SY and Qursishi A (2001) Callus induction, Regeneration and Hygromycin selection of rice (Super Basmati). Journal of Biological Sciences 1(12): 11451146. DOI: $10.3923 /$ jbs.2001.1145.1146

Ratnayake RMLK and Hettiarachchi GHCM (2010) Development of an efficient Agrobacterium mediated transformation protocol for Sri Lankan rice variety - Bg 250. Journal of Tropical Agricultural Research 22(1): 45-53.

Saghai-Maroof MA, Soliman KM, Jorgensen RA and Allard RW (1984) Ribosomal DNAsepacer-length polymorphism in barley: mendelian inheritance, chromo- somal location, and population dynamics. Proc. Natl. Acad. Sci 81: 8014. DOI: $10.1073 /$ pnas.81.24.8014

Sawers RJ, Sheehan MJ and Brutnell TP (2005) Cereal phytochromes: targets of selection, targets for manipulation? Trends in Plant Sciences 10: 138-143. DOI: 10.1016/j.tplants.2005.01.004

Sharkey T D, Vassey TL, Vanderveer PJ, Vierstra RD (1991) Carbon metabolism enzyme and photosynthesis in transgenic tobacco (Nicotiana tobaccum) having excess phytochrome. Planta 185: 287 -296.

Smith DJ, Proudfoot A, Friedli L, Klig LS, Paravicini G and Payton MA (1992) PMI40, an intron-containing gene required for early steps in yeast mannosylation. Molecular \& Cellular Biology 12: 2924-2930. DOI: 10.1128/MCB.12.7.2924

Thiele A, Herold M, Lenk I, Quail PH and Gatz C (1999) Heterologous expression of Arabidopsis phytochrome B in transgenic potato influences photosynthetic performance and tuber development. Plant Physiology 120:73-81. DOI: 10.1104/pp.120.1.73

Wang H and Deng XW (2002) Arabidopsis FHY3 defines a key phytochrome A signaling component directly interacting with its homologous partner FAR1. EMBO J, 21(6):1339 -1349. DOI: 10.1093/emboj/21.6.1339

Wu YY, Chen QJ, Chen M, Chn J and Wang XC (2005) Salttolerant transgenic perennial ryegrass (Lolium perenne $\mathrm{L}$.) obtained by Agrobacterium tumefaciens-mediated transformation of the vacuolar $\mathrm{Na}+\mathrm{H}+$ antiporter gene. Plant Science 169(1):65-73. DOI: 10.1016/j.plantsci.2005.02.030 